\title{
Physical Analysis of Low-dynamic Magnetic Field Impact on Human Tissue
}

\author{
Aleš Richter ${ }^{1)}$, Želmíra Ferková ${ }^{2)}$ and Václav Bittner ${ }^{3)}$ \\ 1) Technical University of Liberec, Institute of Mechatronics and Computer Engineering, Liberec, Czech Republic, \\ e-mail: ales.richter@tul.cz \\ 2) Technical University of Košice, Department of Electrical Engineering \& Mechatronics, Košice, Slovakia, \\ e-mail: zelmira.ferkova@tuke.sk \\ 3) Technical University of Liberec, Faculty of Science, Humanities and Education, Liberec, Czech Republic, \\ e-mail:vaclav.bittner@tul.cz
}

\begin{abstract}
This article makes an effort to explain physical aspects of low-dynamic magnetic field in the human tissue. The principles of electromagnetic induction in the muscle tissue as a typical example of parts of human body are briefly presented. The problems are indicated by modelling. One of the goals is to warn about different distribution of magnetic field in parts of body caused by metal implants. Another analyse introduces physical and energy differences among individual types of power sources of magnetic field and their dynamic behaviour.
\end{abstract}

Keywords - Low-dynamic magnetic field, electromagnetic induction, human tissue, metal human implant, magneto-therapy, $3 D$ modelling of electromagnetic field.

\section{INTRODUCTION}

Every living creatures by own activities produce electromagnetic field. Has external low frequency magnetic field influence on living structure?

In comparison with Reference of ICNIRP committee, e.g. [2], the value of the induced current density ranges from 0.01 to $0.1\left[\mathrm{~A} \cdot \mathrm{m}^{-2}\right]$ in the human body and can influence the nervous system. The range from 0.1 to 1 $\left[\mathrm{A} \cdot \mathrm{m}^{-2}\right]$ is able to cause health hazard and the changes in stimulation of the nervous system were detected.

For this reason it is important to investigate distribution of magnetic field in the human body.

This article does not solve medical problems in any case and presents mainly theoretical physical point of view, e.g. $[1,2]$. The following text makes an effort to explain possible practical aspects of the low-dynamic magnetic field in the human tissue. The principles of electromagnetic induction in the anisotropic muscle tissue as a typical example of parts of the human body are briefly presented.

\section{OVERWIEW OF THEORETICAL PHYSICAL CONDITIONS}

In theory the induced energy of magnetic field in the tissue is shown. The fundamental description of magnetic effect on the living organism is described in many articles and books. These texts, particularly medical literature, very often present the studies in different physical units.

\section{A. Determination of PhysicalUnits}

For unified description it is very important to present the definition of physical quantities and units in international system of units (SI), e.g. [4, 5].

$\gamma_{\mathrm{t}}$ - conductivity of the tissue

$\mathbf{J}_{\mathbf{t}}-$ current density in the tissue

$[\mathrm{S} / \mathrm{m}],\left[\mathrm{m}^{-3} \mathrm{~kg}^{-1} \mathrm{~s}^{3} \mathrm{~A}^{2}\right]$

$\mathbf{E}_{\mathrm{t}}$ - electric field intensity in the tissue

$\left[\mathrm{A} / \mathrm{m}^{-2}\right]$

$[\mathrm{V} / \mathrm{m}],\left[\mathrm{m} . \mathrm{kg} . \mathrm{s}^{-3} \mathrm{~A}\right]$

$\mathrm{W}_{\mathrm{m}}$ - density of magnetic energy coming into the tissue

$\mathbf{H}_{\mathrm{m}}$ - external magnetic field intensity $\begin{array}{r}{\left[\mathrm{J} / \mathrm{m}^{3}\right],\left[\mathrm{m}^{-1} \mathrm{~kg} \cdot \mathrm{s}^{-2}\right]} \\ {[\mathrm{A} / \mathrm{m}]}\end{array}$

$\mathrm{w}_{\mathrm{t}}$ - density of energy absorbed by the tissue

$\mathbf{B}_{\mathrm{m}}$ - external magnetic flux density in the tissue

$\left[\mathrm{J} / \mathrm{m}^{3}\right],\left[\mathrm{m}^{-1} \mathrm{~kg} \cdot \mathrm{s}^{-2}\right]$

$[\mathrm{T}],\left[\mathrm{kg} \cdot \mathrm{s}^{-2} \mathrm{~A}^{-1}\right]$

$\mathrm{W}_{\mathrm{m}}$ - total magnetic energy coming into the tissue [J]

$\mathrm{P}_{\mathrm{m} \text { max }}-$ maximum magnetic power coming into the tissue

$\mathrm{p}_{\mathrm{t}}$ - density of power absorbed by the tissue

$[\mathrm{W}]$

$\left[\mathrm{W} / \mathrm{m}^{3}\right]$

\section{B. Energy Balance}

The tissues and human and animal bodies mainly consist of diamagnetic substances. The magnetic fields penetrate through all parts of the body without difficulty and external magnetic field intensity $\mathbf{H}_{\mathrm{m}}$ is slightly attenuated. The fractional reduction of the magnetic field in the living tissue is caused by a variation of electron orbits of atoms or molecules and it is less than 10 millionths. The variable external magnetic field is transformed into the electric field intensity $\mathbf{E}_{\mathrm{t}}$ in the tissue. According to Ohm's law the electric field intensity produces current density $\mathbf{J}$ because the tissue is adequately conductive $\gamma_{\mathrm{t}}$, e.g. [6]. The product of the electric field intensity $\mathbf{E}$ and current density $\mathbf{J}$ indicate power density $\mathrm{w}_{\mathrm{t}}$ which is absorbed in the tissue. We suppose that external magnetic field is low frequency up to $1 \mathrm{MHz}$ and therefore dielectric losses are not taken into account.

It seems it is possible to use the $2^{\text {nd }}$ Maxwell equation or Faraday's induction law for the deduction of theory. These rules can offer optimal and good solution in electrical machines but they are not suitable for electromagnetic circuits with distributed parameters, e.g. [4]. We take these arguments into consideration and for that reason we used energy conversion principle (see equation 1 ). 


$$
\mathbf{J} \cdot \mathbf{E}=\frac{\mathrm{J}^{2}}{\gamma}+\operatorname{div}(\mathbf{E} \times \mathbf{H})+\frac{\partial \mathrm{w}}{\partial \mathrm{t}}
$$

The third part of the right side of the previous equation (1) presents time derivation of energy density of the electric and magnetic fields in the matter (1.1).

$$
\mathrm{w}=\mathrm{w}_{\mathrm{e}}+\mathrm{w}_{\mathrm{m}}=\frac{1}{2}(\mathbf{E} \cdot \mathbf{D}+\mathbf{H} \cdot \mathbf{B})
$$

Let's assume that the part of the body is penetrated by the external source of magnetic field; only on that account we can simplify the general energy conversion principle. The result is presented as equation (2). The partial equation (2) shows the power density $p_{t}$ in the tissue induced by the time variable current of the external magnetic field.

$$
\begin{aligned}
& \mathrm{p}_{\mathrm{t}}=\frac{\partial \mathrm{w}_{\mathrm{m}}}{\partial \mathrm{t}}=\mathbf{J}_{\mathrm{t}} \cdot \mathbf{E}_{\mathrm{t}}=\gamma_{\mathrm{t}} \mathrm{E}_{\mathrm{t}}^{2}=\frac{\mathrm{J}_{\mathrm{t}}^{2}}{\gamma_{\mathrm{t}}} \\
& \frac{\partial \mathrm{w}_{\mathrm{m}}}{\partial \mathrm{t}}=\mu \mathbf{H}_{\mathrm{m}} \frac{\partial \mathbf{H}_{\mathrm{m}}}{\partial \mathrm{t}}=\mathbf{H}_{\mathrm{m}} \frac{\partial \mathbf{B}_{\mathrm{m}}}{\partial \mathrm{t}}
\end{aligned}
$$

One of the important parameter how to define the effect of the variable magnetic field in the tissue is electric field intensity $\mathbf{E}_{\mathrm{t}}$ (see equation 3 ).

$$
\mathrm{E}_{\mathrm{t}}=\left(\frac{\mu}{\gamma_{\mathrm{t}}} \mathbf{H}_{\mathrm{m}} \frac{\partial \mathbf{H}_{\mathrm{m}}}{\partial \mathrm{t}}\right)^{\frac{1}{2}}
$$

Medical literature defines this biophysical effect with the current density in the tissue $\mathbf{J}_{\mathrm{t}}\left[\mathrm{A} / \mathrm{m}^{2}\right]$ or $\left[\mathrm{A} / \mathrm{cm}^{2}\right]$ (4), $1\left[\mathrm{~A} / \mathrm{m}^{2}\right]$ correspond to $100\left[\mu \mathrm{A} / \mathrm{cm}^{2}\right]$ or $0.1\left[\mathrm{~mA} / \mathrm{cm}^{2}\right]$. This parameter is significant for statement of nonhazardous levels of magnetic field e.g. [1, 2]. We can describe the local current density in the tissue as follows:

$$
\mathbf{J}_{\mathrm{t}}=\left(\mu \gamma_{\mathrm{t}} \mathbf{H}_{\mathrm{m}} \frac{\partial \mathbf{H}_{\mathrm{m}}}{\partial \mathrm{t}}\right)^{\frac{1}{2}}
$$

The important parameter how to evaluate the impact of the external magnetic field is energy density absorbed in the tissue. This situation is presented by the following equations (5). The density of energy in the tissue $w_{t}$ (see equation 5) is a local parameter valid for actual time intervals and space in the part of the body.

The variable external magnetic field is transformed into the electric field intensity $\mathbf{E}_{\mathrm{t}}$ in tissue. The product of electric field intensity $\mathbf{E}_{\mathrm{t}}$ and current density $\mathbf{J}_{\mathrm{t}}$ indicate power density $\mathrm{w}_{\mathrm{t}}$ which is absorbed in the tissue. This follows from $2^{\text {nd }}$ Maxwell equation or Faraday's induction law.

According to Ohm's law

$$
\mathbf{J}_{\mathrm{t}}=\gamma_{\mathrm{t}} \mathbf{E}_{\mathrm{t}}
$$

the electric field intensity produces current density $\mathbf{J}_{\mathbf{t}}$ because the tissue is adequately conductive $\gamma_{t}$, e.g. [7].

$$
\mathrm{w}_{\mathrm{t}}=\int_{\mathrm{t}_{1}}^{\mathrm{t}_{2}} \mathbf{J}_{\mathrm{t}} \cdot \mathbf{E}_{\mathrm{t}} \mathrm{dt}=\gamma_{\mathrm{t}} \int_{\mathrm{t}_{1}}^{\mathrm{t}_{2}} \mathrm{E}_{\mathrm{t}}{ }^{2} \mathrm{dt}=\frac{1}{\gamma_{\mathrm{t}}} \int_{\mathrm{t}_{1}}^{\mathrm{t}_{2}} \mathrm{~J}_{\mathrm{t}}{ }^{2} \mathrm{dt}
$$

$$
\mathrm{w}_{\mathrm{t}}=\mu \int_{\mathrm{t}_{1}}^{\mathrm{t}_{2}} \mathbf{H}_{\mathrm{m}} \frac{\partial \mathbf{H}_{\mathrm{m}}}{\partial \mathrm{t}} \mathrm{dt}=\frac{1}{2} \mu\left[\mathrm{H}_{\mathrm{m}}^{2}\right]_{\mathrm{t}_{1}}^{\mathrm{t}_{2}}
$$

Equation (6.2) applies solely provided that:

- Vector $\mathbf{H}_{\mathrm{m}}$ and its time derivations have in the point identical direction.

- The scalar function $\mathrm{H}_{\mathrm{m}}$ and its time derivation are continuous in the time interval $\left[\mathrm{t}_{1} ; \mathrm{t}_{2}\right]$.

We expect that this power-producing parameter would be more important for evaluation of the magnetic field efficiency.

It is evident that the magnetic field impact depends on the content of the tissue which is inserted into the space of the operating external field. This situation is described by equation (7).

$$
\mathrm{W}_{\mathrm{t}}=\int \mathrm{w}_{\mathrm{t}} \mathrm{dV}
$$

This relation represents the total energy loss and it is given by cubic integral (7), e.g. $[4,5]$.

Other way how to define impact of the magnetic field in the human body is expression of the instantaneous power. This situation is described by equation (8).

$$
P_{t}=\int p_{t} d V=\frac{d}{d t} \int_{V} w_{m} d V=\int_{V} \mathbf{J}_{t} \cdot E_{t} d V
$$

Equation (8) is derived from the integral representation of energy conversion principle which is presented in equation (1). Equation (2) is transformed in this way.

\section{Electromagnetic Properties of Tissues in Frequency

\begin{tabular}{|c|c|}
\hline Conductivity & $\gamma_{\mathrm{t}}[\mathrm{S} / \mathrm{m}]$ \\
\hline Blood & $0.43-0.94$ \\
\hline Cartilage & $0.90-1.10$ \\
\hline Muscle along & $0.15-0.67$ \\
\hline Muscle across & $0.04-0.42$ \\
\hline Bone (Cancellous) & $0.04-0.17$ \\
\hline Subcutaneous fat & $0.02-0.17$ \\
\hline Brain & $0.11-0.45$ \\
\hline
\end{tabular} Range upto $1 \mathrm{MHz}$}

The tissues and human and animal bodies mainly consist of diamagnetic substances. The diamagnetism is too weak, that is why we can count in permeability of vacuum $\mu_{0}$. The frequency of the external magnetic field is low and therefore dielectric losses are not taken into account. The following Table I. presents conductivity of selected typical tissues only [7].

TABLE I.

The CHARACTERISTIC CONDUCTIVITY OF REPRESENTATIVE TISSUES ${ }^{[7]}$

The examples of the tissue conductivity show that the human or animal body is strongly heterogeneous surrounding from electromagnetic view. We can speculate about a low intensity of external electromagnetic field so 
the conductivity of an individual tissue is linear. The ones of tissues (particularly muscle and brain) are anisotropic. The magnetic field direction has substantial influence on physical effect in each tissue point.

\section{Modelling OF EleCtRomagnetiC EFFECT IN LEAVING TISSUE}

The classic examples of a low frequency magnetic field impact on the human body are application in physiotherapy and rehabilitations.

Physiotherapy and rehabilitation use several types and sizes of magnetic applicators for magneto therapy application. These magnetic adapters can be classified as the applicators with open or closed magnetic circuit. Comparatively great cylindrical coil is very popular in medical offices, that is why we chose these types for our experiments. These coils do not include ferromagnetic core and the magnetic field is continuous.

\section{A. Specification of Experiment, Source of Magnetic Field}

This presented magnetic applicator type is the bigger one which is used in magneto therapy and rehabilitation care. The large profile along with relatively short length of the open air coil does not allow creating inside sufficient large space of homogenous magnetic field. The magnetic applicator (according to Fig. 1) is the open air coil without ferromagnetic pole extension. The device design is frameless and therefore the profile of the coil is slightly ellipsoidal.

TABLE II.

THE CIRCUIT PARAMETERS OF MAgNETO THERAPY COIL

$\begin{array}{lll}\text { Inner Inductance } & \mathrm{L}=0.05 & {[\mathrm{H}]} \\ \text { DC resistance } & \mathrm{R}_{\mathrm{DC}}=15 & {[\Omega]} \\ \text { Number of turns } & \mathrm{n}=335 & {[]} \\ \text { Winding length } & 1=340 & {[\mathrm{~mm}]} \\ \text { Ellipse axis } & 600 \times 560 & {[\mathrm{~mm}]}\end{array}$
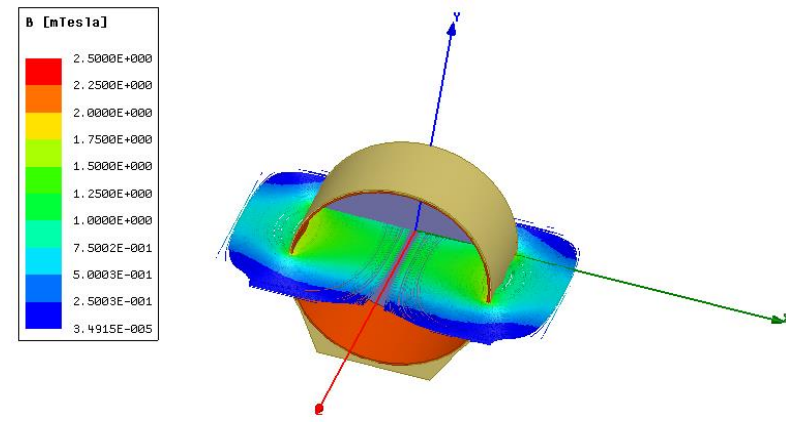

Fig. 1. Magnetic field of elliptic magnetic coil (Tab. II).

In this case the maximum current in the coil (Fig. 1) is chosen $2 \mathrm{~A}$. The distribution of the magnetic flux density is shown in Fig. 2.

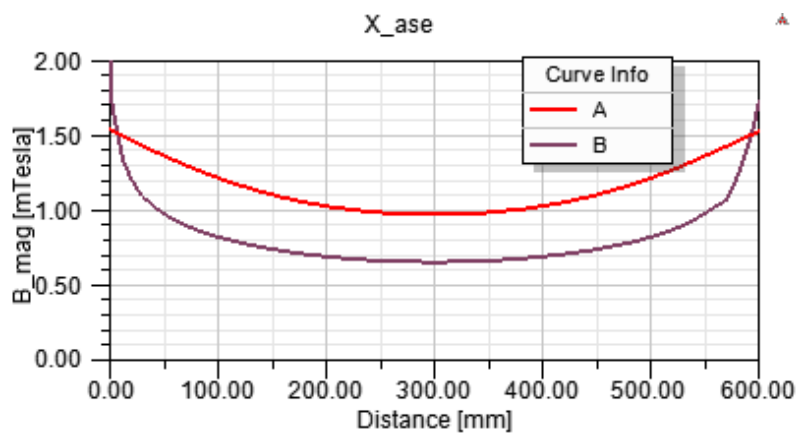

Fig. 2. Distribution of magnetic flux density B inside cylindrical magnetic coil (input current 2 A)

Violet curve shows distribution along the $x$ axis on periphery of the coil and red curve is according the $x$ axis in the centre.

The simulation verifies our assumption that the lowest field intensity is right in the point of intersection between the axis $y$ and axis $z$ in the center. The level of magnetic flux density $\mathbf{B}$ can range in units [mT]. In comparison with the geomagnetic flux density $\left(\mathbf{B}_{\text {geomg }} \sim 30 \div 50[\mu \mathrm{T}]\right)$ this application of the magneto therapy used more than hundredfold more powerful magnetic flux density, [3].

\section{B. Simple Model of Leg and his Location and Orientation in Magnetic Field}

In our simulation is used simple model of a leg which is placed off-center (Fig. 3). This approximation is imperative to indicating energy effects in the model of a leg.

The position of the treated body part in the center of coil is not optimal for therapy but we can see this positioning in medical praxis very often.

The low-frequency magneto therapy uses particular sequences of rectangular voltage pulses generated on the input of a coil. For this reason the simulation is implemented on one pulse of the therapeutic sequence only.

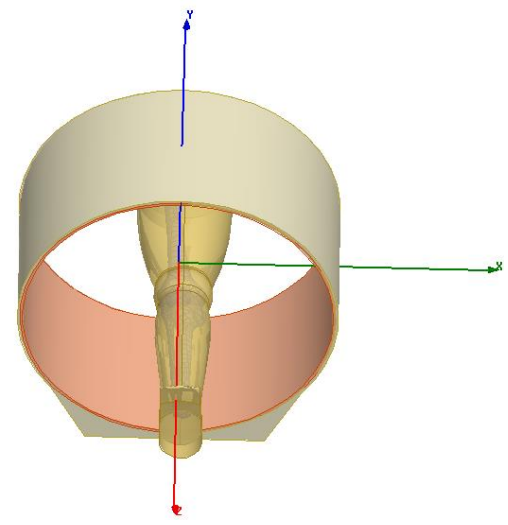

Fig. 3.1. Location of the leg in modelling and magnetic vectors specification. Model of a leg in accordance with $166 \mathrm{~cm}$ stature and $66 \mathrm{~kg}$ weight of woman figure. 


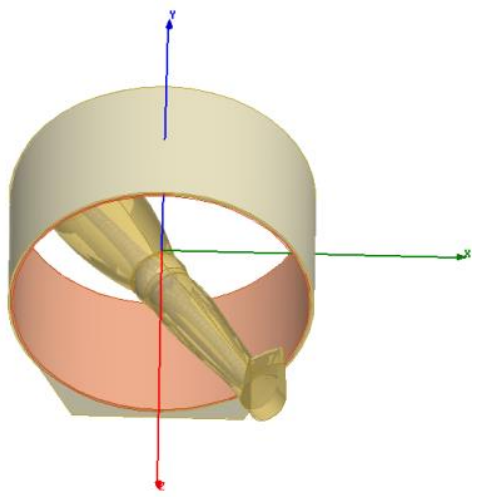

Fig. 3.2. Location of a leg in modelling, rotation $30^{\circ}$ in the $\mathrm{x}, \mathrm{y}$ lines.

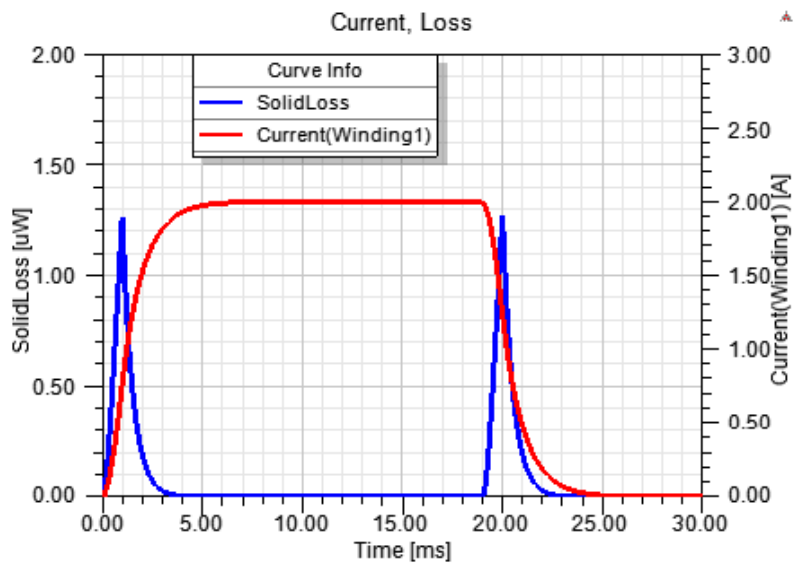

Fig. 4.1. The time form of individual current pulse (red) in coil of cylindrical applicator. The blue time form of induction losses in tissue of a leg in along direction. $\mathrm{P}_{\mathrm{m} \max } \sim 1,3[\mu \mathrm{W}]$.

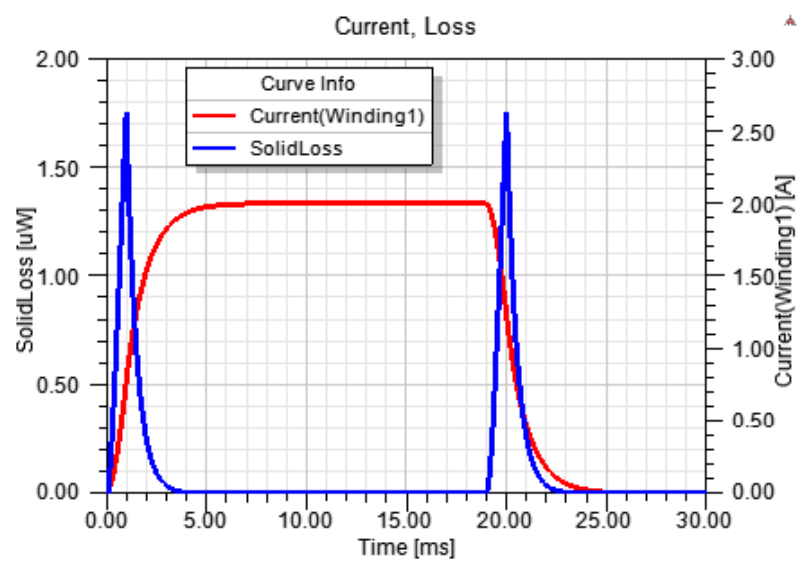

Fig. 4.2. The time form of individual current pulse (red) in coil of cylindrical applicator. The blue time form of induction losses in tissue of a leg, rotation $30^{\circ}$ in the $\mathrm{x}, \mathrm{y}$ lines, $\mathrm{P}_{\mathrm{m} \max } \sim 1,75[\mu \mathrm{W}]$.

\section{DISCUSSION}

This paper does not solve medical clinical problems but emphasis is put on physical aspect. For future research is important to find appropriate model of the body reflecting differences among inductivity of fatty tissue, muscle, blood, bone etc.
The total energy impact of the low frequency artificial magnetic flux density in range of [mT] units is insignificant and it does not achieve increasing local temperature in the body. Thermoregulatory system of the body is much effective and this energy allowance is compensated in other parts of the body. The current density is continuously distributed in the body and therefore it is impossible to focus on the right place. Unfortunately, they cannot be found in analytical form, since the human body is a very complicated medium. More information about the field in the body can be found by the use of FEM methods. But its use is not simple and the extraction of practical results from the solution is complicated.

Electromagnetic theory only gives the fields in the body with certain accuracy. They affect the ions in the body. It is possible to describe the forces acting on the ions and its motion. It is the purpose of the paper. The understanding of medical effects needs a close cooperation of physical and medical specialists.

Approximate solution describes the induced electric field.

The location and orientation of the body, volume exposed tissue and their composition have strong effect on distribution of the induced field and its energy impact. The metal implants in the body pose health hazard.

\section{ACKNOWLEDGMENT}

This work was supported from institutional support for long term strategic development of the Ministry of Education, Youth and Sports of the Czech Republic.

This work was supported by the Slovak Research and Development Agency under the contract No. APVV-150750 and project ITMS 26220220182.

\section{REFERENCES}

[1] P. Brodeur, Annals of Radiation: The hazards of electromagnetic fields. Parts 1-3. New York, 12 June, 51-88; 19 June, 47-73; 26 June, 39-68, 1989. (Later published as Currents of death: Power lines, computer terminals and the attempt to cover up their threat to your health. New York: Simon and Schuster, 1989).

[2] Reference of ICNIRP committee: Guidelines for Limiting Exposure to Time-Varying Electric, Magnetic, and Electromagnetic Fields (up to $300 \mathrm{GHz}$ ). Health Physics 74/ 4: 494-522, 1998.

[3] L. Slavík, J. Rosický, and M. Novák, "Optimization of magnetic circuit in electromagnetic flow meter," 17th International Carpathian Control Conference, ICCC 2016. Slovakia: Institute of Electrical and Electronics Engineers Inc., 2016. pp. 688-691. https://doi.org/10.1109/CarpathianCC.2016.7501183

[4] S.U. Inan and S.A. Inan, Engineering Electromagnetics. AddisonWesley, Menlo Park, CA, USA, 1999. ISBN 0-201-47473-5.

[5] D. Mayer, Theory of Electromagnetic field (in Czech). ZČU Plzeň, March 2004, publication no. 1628.

[6] D. Mayer, Applied Electromagnetisms (in Czech). České Budějovice: Kopp, 2012. ISBN 9788072324361.

[7] https://www.itis.ethz.ch/virtual-population/tissue-properties/ database/low-frequency-conductivity/

[8] A. Richter, Ž. Ferková, "Physical and energy analysis of therapy applying low-dynamic magnetic fields," in 2017 IEEE International Workshop of Electronics, Control, Measurement, Signals and their Application to Mechatronics (ECMSM), May 201. https://doi.org/10.1109/ECMSM.2017.7945889 